\title{
Salmonella Heidelberg Isolated from Poultry Shows a Novel Resistance Profile
}

\author{
Gabriella Bassi das Neves², Lenita Moura Stefani ${ }^{1,2}$, Eduarda Pick', Denise Nunes Araujo ${ }^{1,2}$, \\ Jéssica Giuriatti' ${ }^{2}$, Cleverson Percio' \& Maiara Cristiane Brisola²
}

\begin{abstract}
Background: The development of antimicrobial resistance in bacteria is a serious public health issue worldwide. Salmonella spp. is considered a leader cause of gastrointestinal disease in animals and humans, and poultry products have been reported as an important reservoir of the bacterium. S. Heidelberg became lately one of the most prevalent serovars found in several countries. However, hardly any information is available about the epidemiology and the resistance profile of it. Therefore, the objective of this study was to determine the antibiotic resistance profile of $S$. Heidelberg (SH) and to compare to $S$. Enteritidis (SE) and $S$. Typhimurium (ST) isolated from the Southern part of Brazil.

Materials, Methods \& Results: A total of 162 Salmonella isolates of poultry origin serotyped as SH (54), SE (54), and ST (54) were submitted to the disk-diffusion test with disks containing 10 antibiotics of 7 different classes, routinely used in veterinary and human medicine such as: enrofloxacin, ciprofloxacin, norfloxacin, gentamicin, ceftiofur, ceftriaxone, nalidixic acid, tetracycline, sulfamethoxazole-trimethoprim, and chloramphenicol. In addition, the Multi-drug Resistance Pattern (MDRP) and the Multiple-Drug Resistance Index (MDRI) were determined. The Chi-square $\left(\chi^{2}\right)$ test with $1 \%$ of significance level was used to statistically evaluate the results. All isolates were susceptible to norfloxacin, enrofloxacin, and ciprofloxacin. The majority of the isolates were resistant to the quinolone class (68\%), more specifically to nalidixic acid, which is considered a synthetic quinolone, followed by penicillin (47\%) and cephalosporin (16\%). Overall, SH isolates showed higher resistance compared to ST and SE (18, 16.5, and $9.6 \%$, respectively). SH isolated from field samples, mainly drag swabs, showed higher resistance levels (24.2\%) than those isolated from slaughterhouses (5.6\%). SH showed the highest percentage of resistance to ceftiofur (31.5\%), ceftriaxone (9.3\%), and tetracycline (64.8\%) in comparison to the other two serotypes. Most of the SH isolates were resistant to at least two (66.7\%), three or more antibiotics (33.3\%). A different scenario was observed for ST and SE, where 25.9 and $9.3 \%$ were susceptible to at least one drug, respectively. The most common pattern of resistance (MDRP) was C (gentamicin - nalidixic acid - tetracycline) for 14 SH isolates, and A (ceftiofur - nalidixic acid - tetracycline) for $12 \mathrm{SH}$ isolates. MDRI indicated that $22.8 \%$ of all isolates were multidrug resistant. SH was the isolate with the largest variety of resistance patterns compared to ST and SE, where $11.7 \%$ of the isolates were resistant to more than three antibiotics. In addition, SH showed the greatest MDRI $(0.25)$ ranging from 0.2 to 0.5 .

Discussion: SH was resistant to almost all antibiotics tested and showed multi-drug resistant profile, therefores, it showed a potential for horizontal transmission of resistance genes. Additionally, SH showed a higher resistance profile for ceftiofur, an important antibiotic used in poultry, which can cross-resist to ceftriaxone, commonly used to treat salmonellosis in children. Our results showed that SH is a real challenge regarding antimicrobial resistance. This scenario leads to the need for rational and judicious use of antimicrobials in poultry and, as an alert to the medical community.
\end{abstract}

Keywords: antibiotics, multidrug resistance, public health, resistance, Salmonella. 


\section{INTRODUCTION}

Salmonellosis is a gastrointestinal disease caused by a bacterium of the genus Salmonella spp., belonging to the family Enterobacteriaceae [6,13]. It is considered an important zoonotic disease worldwide with significant impact in public health. The ingestion of contaminated food is the main source of human contamination. In addition, poultry products, mainly eggs, are considered important reservoirs for Salmonella [3,19].

The $S$. Heidelberg ( $\mathrm{SH}$ ) is among the most common serovar isolated from people infected with salmonellosis in many parts of the world. Despite that, little is known about its epidemiology and resistance profile. Therefore, the objective of this study was to determine the resistance and multidrug resistance profile of isolates of $\mathrm{SH}$ in comparison to $S$. Enteritidis (SE) and $S$. Typhimurium (ST) isolated from poultry meat plants and farms of few states of Southern Brazil.

\section{MATERIALS AND METHODS}

Salmonella isolates

All Salmonella spp. samples used in this study were of poultry origin (132 field samples and 30 slaugtherhouses) as described in Table 1. It were analyzed 162 isolates of $S$. Enteritidis, $S$. Typhimurium and $S$. Heidelberg, reaching a total of 54 isolates for each sorovar. They were isolated in 2009 to 2013 in three Brazilian Southern states (Paraná, Santa Catarina, and Rio Grande do Sul) where approximately $73 \%$ of all exported meat is produced [2]. Samples were isolated by two laboratories: a private veterinary laboratory accredited by the Ministry of Agriculture, Livestock and Food Supply (MAPA), and a laboratory at the State Agricultural Foundation (FEPAGRO) in the state of Rio Grande do Sul. Later, these isolates were serotyped by the Oswaldo Cruz Foundation (FIOCRUZ). At the Laboratory of Molecular Biology, Immunology and Microbiology (LABMIM) of the State University of Santa Catarina (UDESC) all samples were subcultured following the methodology of conservation and maintenance for the microorganism [16].

\section{Disk-diffusion tests}

Disk-diffusion tests were performed in the LABMIM using the methodology approved by the NCCLS (National Committee for Clinical Laboratory Standards) and ANVISA (National Health Surveillance Agency) contained in the Normative Instruction number M-2, Standardization A-8 of Antimicrobial Susceptibility Testing by Disco-diffusion [1]. Antimicrobial discs ${ }^{1}$ used to verify the sensitivity of the 162 isolates were: enrofloxacin $(5 \mu \mathrm{g})$, ciprofloxacin $(5$ $\mu \mathrm{g})$, norfloxacin $(10 \mu \mathrm{g})$, gentamicin $(10 \mu \mathrm{g})$, ceftiofur $(30 \mu \mathrm{g})$, ceftriaxone $(30 \mu \mathrm{g})$, nalidixic acid $(30 \mu \mathrm{g})$, tetracycline $(30 \mu \mathrm{g})$, sulfamethoxazole-trimethoprim $(25 \mu \mathrm{g})$ and chloramphenicol $(30 \mu \mathrm{g})$. Escherichia coli $\mathrm{ATCC}^{\circledR} 25922^{2}$ was used as a reference strain. Isolates were classified as sensitive or resistant.

Table 1. Number of $S$. Heidelberg, $S$. Enteritidis, and $S$. Typhimurium according to their origin of isolation.

\begin{tabular}{|c|c|c|c|}
\hline \multicolumn{2}{|r|}{ Field } & Total & $\begin{array}{c}\text { Number of } \\
\text { samples } \\
(\mathrm{SH} / \mathrm{SE} / \mathrm{ST})^{*}\end{array}$ \\
\hline \multirow{4}{*}{$\begin{array}{l}\text { Broiler } \\
\text { houses }\end{array}$} & Cupboard boxes & 2 & $0 / 2 / 0$ \\
\hline & Drag swabs & 78 & $28 / 13 / 37$ \\
\hline & Meconium & 2 & $0 / 2 / 0$ \\
\hline & Feces & 1 & $0 / 1 / 0$ \\
\hline \multirow{3}{*}{ Hatcheries } & Pipped eggs & 2 & $0 / 2 / 0$ \\
\hline & Yolk sacs & 8 & $0 / 4 / 4$ \\
\hline & Feathers & 1 & $0 / 1 / 0$ \\
\hline \multirow{2}{*}{ Feedmills } & Feed paper bags & 1 & $0 / 1 / 0$ \\
\hline & Bonemeal & 1 & $0 / 0 / 1$ \\
\hline \multirow{6}{*}{$\begin{array}{c}\text { Organs from } \\
\text { broilers at } \\
\text { necropsy }\end{array}$} & Dead broilers & 6 & $2 / 4 / 0$ \\
\hline & Cecum & 2 & $0 / 1 / 1$ \\
\hline & Spleen & 1 & $0 / 0 / 1$ \\
\hline & Intestines & 3 & $0 / 3 / 0$ \\
\hline & Crop & 1 & $0 / 0 / 1$ \\
\hline & Bursa of Fabricius & 1 & $0 / 0 / 1$ \\
\hline & $\begin{array}{c}\text { Culture } \\
\text { (miscellaneous) }\end{array}$ & 22 & $6 / 9 / 7$ \\
\hline & Field total & 132 & $36 / 43 / 53$ \\
\hline \multicolumn{4}{|c|}{ Slaughterhouse } \\
\hline \multirow{7}{*}{$\begin{array}{l}\text { Poultry } \\
\text { products }\end{array}$} & Liver/heart & 1 & $0 / 1 / 0$ \\
\hline & Neck & 1 & $0 / 1 / 0$ \\
\hline & Broiler meat (parts) & 24 & $18 / 6 / 0$ \\
\hline & Wings & 1 & $0 / 1 / 0$ \\
\hline & $\begin{array}{l}\text { Meat mechanically } \\
\text { separated (CMS) }\end{array}$ & 1 & $0 / 1 / 0$ \\
\hline & Whole carcass & 1 & $0 / 0 / 1$ \\
\hline & Broiler thighs & 1 & $0 / 1 / 0$ \\
\hline \multicolumn{2}{|c|}{ Slaugtherhouse total } & 30 & $18 / 11 / 1$ \\
\hline \multicolumn{2}{|c|}{ TOTAL } & 162 & $54 / 54 / 54$ \\
\hline
\end{tabular}

*SH: $S$. Heidelberg; SE: $S$. Enteritidis; ST: $S$. Typhimurium.

\section{Multi-drug Resistance Pattern (MDRP)}

According to the disk-diffusion data, it was possible to determine the number of isolates that were resistant to three or more antibiotics, e.g. those truly 
multi-drug resistant [5]. Resistant samples were classified into six patterns:

ceftiofur - nalidixic acid - tetracycline (A); ceftiofur - ceftriaxone - nalidixic acid (B); gentamicin - nalidixic acid - tetracycline $(\mathrm{C})$; ceftiofur - ceftriaxone - nalidixic acid - tetracycline (D);

ceftiofur - gentamicin - nalidixic acid - tetracycline (E);

ceftiofur - gentamicin - ceftriaxone - nalidixic acid - tetracycline $(\mathrm{F})$.

\section{Multiple-drug Resistance Index (MDRI)}

MDRI was calculated according to the methodology described by Krumperman [7] considering the ratio between the number of drugs that each isolate was resistant and the total number of antimicrobials tested.

\section{Statistical analysis}

The Chi-square $\left(\chi^{2}\right)$ by SAS (2007) with $1 \%$ significance level $(P<0.01)$ was used to statistically evaluate the results from the disk-difusion test.

\section{RESULTS}

\section{Disk-diffusion test}

The number and the percentage of resistant isolates of SH, SE, and ST are shown in Table 2. All isolates were susceptible to norfloxacin, enrofloxacin, and ciprofloxacin. The highest resistance percentage was observed for the nalidixic acid reaching $100 \%$ for $\mathrm{SH}$ isolated in the field, followed by tetracycline. Overall, SH isolates showed higher resistance compared to ST and $\mathrm{SE}(18,16.5$, and $9.6 \%$, respectively). SH isolated from field samples showed almost five times more resistance $(24.2 \%)$ than those isolated from slaughterhouses (5.6\%). SH showed the highest percentage of resistance to tetracycline (64.8\%), ceftiofur (31.5\%), and ceftriaxone $(9.3 \%)$ in comparison to the other two serotypes.

All antibiotics were grouped into seven different classes of antibiotics: cephalosporin, fluoroquinolone, aminoglycoside, penicillin, quinolone, chloramphenicol, sulfa-trimethoprim. Figure 1 shows the results of antibiotic resistance for all three sorovars according to the class of antibiotic used. The majority of the isolates were resistant to the quinolone class (68\%), more specifically to nalidixic acid, which is considered a synthetic quinolone, followed by penicillin and cephalosporin.

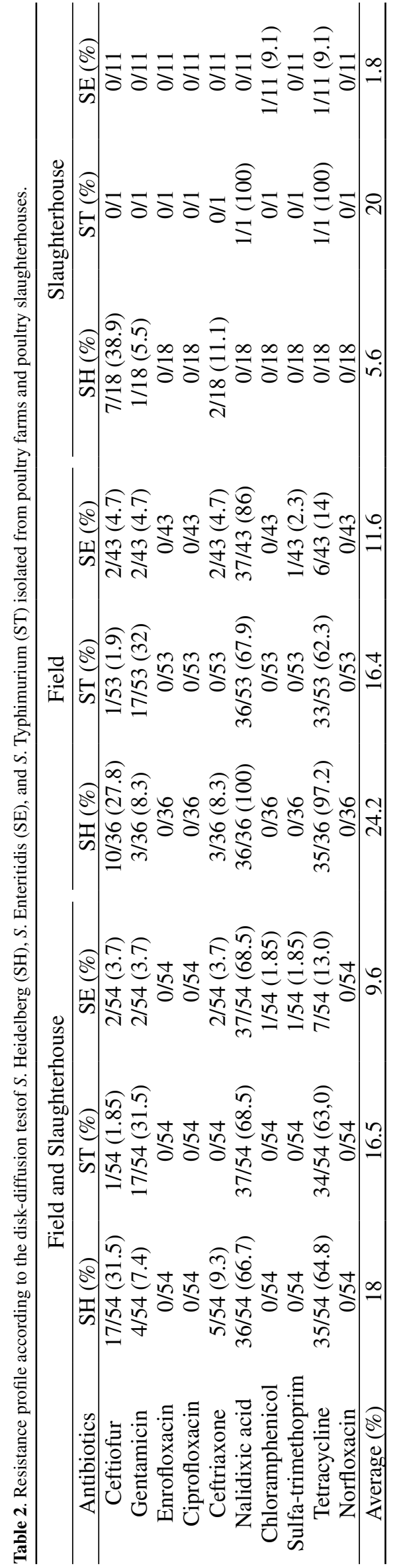


In all cases, there was a significant difference between the resistance profile and the antibiotic tested $(P<0.01)$, except $(P=0.3505)$ for SE and ST isolated from chicken meat (slaughterhouses).

\section{Multi-drug Resistance Pattern (MDRP)}

Table 3 shows the percentage of all three isolates of Salmonella resistant to one, two, three or more antibiotics. All SH isolates showed some percentage of resistance to one or more antibiotics, and most of the $\mathrm{SH}$ isolates were resistant to two (66.7\%), three or more antibiotics (33.3\%). A different scenario was observed for ST and SE, where 25.9 and $9.3 \%$ was susceptible to at least one drug, respectively.

Table 4 shows the MDRP for SH, SE, and ST to three, four and five antibiotics, as well as their MDRI.
Of all the isolates, 30 were resistant to three drugs (18.5\%), 3 were resistant to four drugs, 4 were resistant to five drugs, and none were resistant to more than five antibiotics. The most common profile of resistance found was $\mathrm{C}$ (gentamicin - nalidixic acid - tetracycline) and A (ceftiofur - nalidixic acid - tetracycline). SH was the isolate with the largest variety of resistance patterns, compared to ST and SE.

\section{Multiple-drug Resistance Index (MDRI)}

The mean MDRI for SE, ST and SH isolates was 0.2. Considering each individual isolate, $\mathrm{SH}$ showed the greatest MDRI (0.25), ranging from 0.2 to 0.5 . ST showed mean of $0.17 \mathrm{MDRI}$, ranging from 0 to 0.4 , and SE was the isolated with lower MDRI (0.12), varying from 0 to 0.4 .

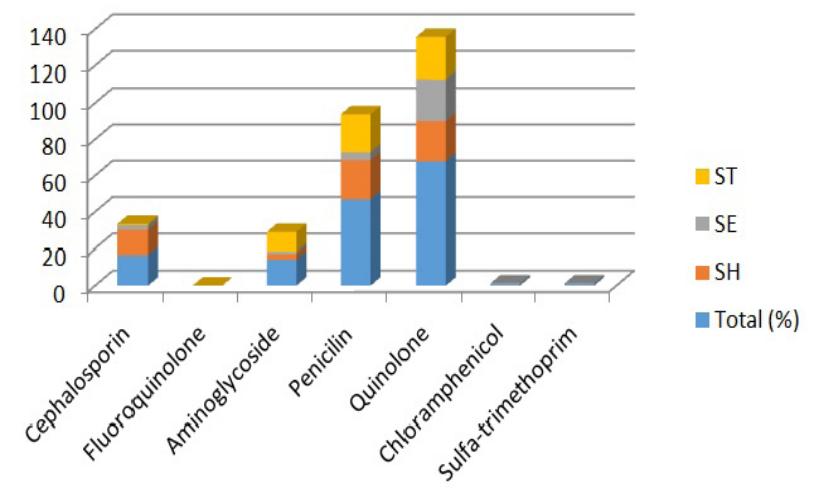

Figure 1. Percentage of resistant $S$. Heidelberg, $S$. Enteritidis and $S$. Typhimurium (Y axis) related to the class of antimicrobials ( $\mathrm{X}$ axis).

Table 3. Isolates of $S$. Heidelberg (SH), S. Enteritidis (SE) and $S$. Typhimurium (ST) of poultry origin resistant to none, one, two, three or more antibiotics (atbs).

\begin{tabular}{|c|c|c|c|c|c|c|c|c|c|}
\hline & \multicolumn{9}{|c|}{ Percentual of multi-drug resistance } \\
\hline & \multirow{2}{*}{ Total } & \multicolumn{2}{|c|}{ none } & \multicolumn{2}{|c|}{$1 \mathrm{atb}$} & \multicolumn{2}{|c|}{2 atbs } & \multicolumn{2}{|c|}{$\geq 3$ atbs } \\
\hline & & $\mathrm{n}$ & $\%$ & $\mathrm{n}$ & $\%$ & $\mathrm{n}$ & $\%$ & $\mathrm{n}$ & $\%$ \\
\hline SE & 54 & 5 & 9.3 & 42 & 77.8 & 3 & 5.6 & 4 & 7.4 \\
\hline ST & 54 & 14 & 25.9 & 6 & 11.1 & 19 & 35.2 & 15 & 27.8 \\
\hline $\mathrm{SH}$ & 54 & 0 & 0 & 0 & 0 & 36 & 66.7 & 18 & 33,3 \\
\hline Total & 162 & 19 & 11.7 & 48 & 29.6 & 58 & 35.8 & 37 & 22.8 \\
\hline
\end{tabular}

Table 4. Multi-drug resistant profile (MDRP) and Multi-drug resistance index (MDRI) of $S$. Heidelberg (SH), $S$. Enteritidis (SE) and $S$. Typhimurium (ST) isolated from poultry.

\begin{tabular}{|c|c|c|c|c|}
\hline Isolate & MDRP & Pattern & MDRI & Total \\
\hline $\mathrm{SH}(12)$ & Ceftiofur-Nal. acid-Tetra & A & 0.3 & 12 \\
\hline $\mathrm{SH}(1)$ & Ceftiofur-Ceftriaxone-Nal acid & B & 0.3 & 1 \\
\hline $\mathrm{SH}(1), \operatorname{SE}(2), \mathrm{ST}(14)$ & Gentamicin-Nal. acid-Tetra & $\mathrm{C}$ & 0.3 & 17 \\
\hline $\mathrm{SH}(1), \mathrm{SE}(1)$ & Ceftiofur-Ceftriaxone-Nal. acid-Tetra & $\mathrm{D}$ & 0.4 & 2 \\
\hline $\mathrm{ST}(1)$ & Ceftiofur-Gentamicin-Nal. acid-Tetra & $\mathrm{E}$ & 0.4 & 1 \\
\hline $\mathrm{SH}(3), \mathrm{SE}(1)$ & Ceftiofur-Gentamicin-Ceftriaxone-Nal. acid-Tetra & $\mathrm{F}$ & 0.5 & 4 \\
\hline \multicolumn{4}{|c|}{ Total of multiresistant isolates } & 37 \\
\hline
\end{tabular}




\section{DISCUSSION}

There is a growing global concern in the emergence of multidrug-resistant strains [5]. Our study found that $\mathrm{SH}$ of poultry origin has an important profile of resistance compared to the other two serotypes. SH was the main serovar responsible for high levels of resistance observed for cephalosporin, especially ceftiofur. Moreover, these SH isolates showed MDRI above 0.3 , indicating a multidrug resistance profile and a great potential for horizontal transmission of resistance genes to other hosts. High IRMA indicates a risk to public health and may hinder the treatment of animal and human diseases, warning for the need of rational use of these drugs [10].

Regarding fluoroquinolones, this study has showed that they could be used to treat salmonellosis. These results were expected, since enrofloxacin is a fluoroquinolone, considered a second generation of quinolones. Our results are corroborated by many authors while evaluating isolates of Salmonella of poultry origin $[4,14,17]$, despite the lack of information specifically for $\mathrm{SH}$.

For many years, nalidixic acid has been used in poultry flocks in Brazil [14]. This study showed that $68 \%$ of the isolates were resistants to this antibiotic, which is different from what was found by other authors that have reported only $26.01 \%$ and $14.56 \%$ of resistance $[9,17]$. An increased incidence of resistance for quinolones in animals has been associated with the use of nalidixic acid in livestock [8]. If only SH was considered, $31.5 \%$ of them were found to be resistant to ceftiofur, a much higher level compared to other study (12.19\%) [18]. A study on 20 isolates of SH between 2005 and 2009 reported that in 2005, 38.4\% of the isolates were resistant to ceftiofur but in 2009 , $100 \%$ of the samples were resistant to the drug [11]. Moreover, lower resistance levels of ceftriaxone were observed, agreeing with our findings [9,12].
Increased resistance to broad-spectrum cephalosporins (ceftiofur and ceftriaxone) among $\mathrm{SH}$, as observed in this study, is of significant interest to public health, since ceftriaxone is an important third generation cephalosporin used to treat children with severe forms of salmonellosis. Considering that the microorganisms resistant to ceftiofur are cross-resistant to ceftriaxone, the use of this antimicrobial agent in food animals is under increased scrutiny, as a potential agent responsible for the emergence and spread of resistance to ceftriaxone in Salmonella spp. and other enteric pathogens $[5,15]$. It can be seen that the tested strains showed a worrying degree of multidrug resistance, which can hinder the treatment of salmonellosis in poultry and humans.

\section{CONCLUSION}

Our results showed a higher percentage of $\mathrm{SH}$ isolates resistant to many antibiotics compared to SE and ST. This profile of multi-drug resistance, including to antibiotics used in humans, requires judicious care by doctors and veterinarians while using these drugs. It is important to point out the need for continued studies on $\mathrm{SH}$, in order to better monitor and control this pathogen that lately is commonly present in the worldwide agrobusiness.

\section{MANUFACTURERS}

${ }^{1}$ Laborclin Produtos para Laboratórios Ltda. Pinhais, PR, Brazil. ${ }^{2}$ Newprov Produtos para Laboratórios. Pinhais, PR, Brazil.

Acknowledgements. We would like to thank LABMIM (UDESC), FAPESC (Foundation for Research and Innovation of Santa Catarina State), and Mercolab Ltda.

Funding. This research was supported by University of Santa Catarina State (UDESC) and FAPESC.

Declaration of interest. The authors report no conflicts of interest. The authors alone are responsible for the content of the paper.

\section{REFERENCES}

1 Agência Nacional de Vigilância Sanitária (ANVISA). 2003. Padronização dos Testes de Sensibilidade a Antimicrobianos por Disco-difusão: Norma Aprovada. 8.ed. 23(1): 58p.

2 Associação Brasileira de Proteína Animal. 2015. Disponível em: <http://www.brazilianchicken.com.br/home/ofrangonomundo>. [Accessed online September 2015].

3 Berchieri Júnior A. \& Oliveira G.H. 2006. Salmoneloses aviárias. In: Andreatti Filho R.L. (Ed). Saúde Aviária e Doenças. São Paulo: Roca, pp.84-111.

4 Duarte D.A.M., Ribeiro A.R., Vasconcelos A.M.M., Santos S.B., Silva J.V.D., Andrade P.L.A. \& Falcão L.S.P.C.A. 2009. Occurrence of Salmonella spp. in broiler chicken carcasses and their susceptibility to antimicrobial agents. Brazilian Journal of Microbiology. 40: 569-573. 
5 Frye J.G. \& Cray P.J. 2007. Prevalence, distribution and characterization of ceftiofur resistance in Salmonella enterica isolated from animals in the USA from 1999 to 2003. Antimicrobial Agents. 30: 134-142.

6 Gyles C.L., Prescott J.F., Songer G. \& Thoen C.O. 2012. Pathogenesis of Bacterial Infection in Animals. 3rd edn. Ames: Blackwell Publishing, pp.143-160.

7 Krumperman P.H. 1983. Multiple antibiotic resistance indexing of Escherichia coli to identify high-risk sources of fecal contamination of foods. Applied and Environmental Microbiology. 46(1): 165-170.

8 Malorny B., Chroeter A. \& Helmuth R. 1999. Incidence of Quinolone Resistance Over the Period 1986 to 1998 in Veterinary Salmonella Isolates from Germany. Antimicrobial Agents and Chemotherapy. 43(9): 2278-2282.

9 Medeiros L.M. 2006. Estudo sobre cepas de Salmonella enterica sorovar Typhimurium resistentes a antimicrobianos isoladas de diferentes fontes da cadeia alimentar no Brasil. 127f. Rio de Janeiro, RJ. Dissertação (Pós-graduação Vigilância Sanitária) - Instituto Nacional de Controle de Qualidade em Saúde Fundação Oswaldo Cruz.

10 Medeiros M.A.N., Oliveira D.C.N., Rodrigues D.P. \& Freitas D.R.C. 2011. Prevalence and antimicrobial resistance of Salmonella in chicken carcasses at retail in 15 Brazilian cities. Revista Panamericana de Salud Publica. 30(6): 555560 .

11 Mion L., Colla F.L., Cisco I.C., Webber B., Diedrich L.N., Pilotto P., Rodrigues L.B., Nascimento V.P. \& Santos L.R. 2014. Perfil de resistência a antimicrobianos por Salmonella Heidelberg isoladas de abatedouro avícola em 2005 e 2009. Acta Scientiae Veterinariae. 42: 1197.

12 Nunes I.A. 2009. Antimicrobial susceptibility of Salmonella Enteritidis strains from different sources. Ciência Animal Brasileira. 10(1): 166-173.

13 Quinn P.J., Markey B.K., Carter M.E., Donnelly W.J. \& Leonard F.C. 2005. Microbiologia Veterinária e Doenças Infecciosas. Porto Alegre: Artmed, 512p.

14 Seyfarth A.M., Wegener H.C. \& Frimodt-moller N. 1997. Antimicrobial resistance in Salmonella enterica subesp. enterica serovar Typhimurium from humans and production animals. Journal of Antimicrobial Chemotherapy. 40: 6775 .

15 Silbergeld E., Graham J. \& Price L.B. 2008. Industrial food animal production, antimicrobial resistance, and human health. Annual Review of Public Health. 29: 15-169.

16 Sola M.C., Oliveira A. P., Feistel J.C. \& Rezende C.S.M. 2012. Manutenção de microrganismos: conservação e viabilidade. Enciclopédia Biosfera. 8(14): 1398-1418.

17 Vaz C.S.L., Streck A.F., Michael G.B., Marks F.S., Rodrigues D.P., Reis E.M.F., Cardoso M.R.I. \& Canal C.W. 2010. Antimicrobial resistance and subtyping of Salmonella enterica subspecies enterica serovar Enteritidis isolated from human outbreaks and poultry in southern Brazil. Brazilian Journal of Poultry Science. 89: 1530-1536.

18 Voss-Rech D., Vaz C.S.L., Alves L., Coldebella A., Leão J.A., Rodrigues D. \& Back A. 2015. A temporal study of Salmonella enterica serotypes from broiler farms in Brazil. Poultry Science. 94: 433-441.

19 Welker C.A.D., Both J.M.C., Longaray S.M., Haas S., Soeiro M.L.T. \& Ramos R.C. 2010. Análise microbiológica dos alimentos envolvidos em surtos de doenças transmitidas por alimentos (DTA) ocorridos no estado do Rio Grande do Sul, Brasil. Revista Brasileira de Biociências. 8(1): 44-48. 